\title{
AN EMPIRICAL STUDY OF KEYWORDS IN ISSUES IN INFORMATION SYSTEMS (2000-2019)
}

\author{
Matthew North, Utah Valley University, mnorth@uvu.edu \\ Thomas Lombardi, University of the Virgin Islands, thomas.lombardi@uvi.edu
}

\begin{abstract}
In 2016, Love \& Hirschheim wrote: "We are wise to take pause periodically in order to reflect on our collective work efforts as researchers. Indeed, it is healthy to take stock of our actual performance in relation to our intended and stated goals." This paper seeks to address and embody the spirit of their sage recommendation. Through text mining and keyword analysis, we examine 20 years of scholarly works disseminated in Issues in Information Systems, an annual publication of the International Association for Computer Information Systems. Nearly 2,100 published papers were examined, revealing more than 5,300 keywords and terms. These topics were then further analyzed to identify foundations, trends and even fads in the body of research. We identify high-volume topics, topic consistency over time, and significant changes over time, in order to define strengths and gaps in information systems research and to encourage meaningful future scholarly study. Our findings reveal three main themes. 1) Throughout the 20 year period of analysis certain research topics such as knowledge management and information security emerge as enduring and foundational. 2) Some unexpected changes occurred, exemplified by a shift from a high number of e-commerce papers early on, to a lower number of papers recently (Dennis, 2017). And 3) Topics have burst onto the scene with a quick rise in the number of papers (e.g. 'Cybersecurity', in the past five years); though not all endured (e.g. 'Virtual Worlds' during the mid-2000's). With this paper, we seek to learn lessons from past inquiry, assess the current state of affairs among our community of scholars, and illuminate opportunities for quality research into the future.
\end{abstract}

Keywords: information systems research, technology trends, keyword analysis, digital image processing

\section{INTRODUCTION}

Observers of the first two decades of the Twenty-First Century have witnessed rapid changes in the fields of information systems (IS) and information technology (IT). The role of computing in the day to day operations and activities of businesses worldwide, and in essentially every industry, is now ubiquitous. Therefore, research into the practice and pedagogy of IS and IT is of paramount importance to prepare leaders and workers for full participation in Information Age enterprises. For the past 20 years, the International Association for Computer Information Systems (IACIS) has annually published Issues in Information Systems (IIS). This publication, which coincides with the association's annual conference each October, provides a scholarly outlet for hundreds of researchers each year.

In this study, we examine the papers published in IIS between the years 2000 and 2019. This comprises IIS volumes one through 20, most of which are available through open access on the association's website (https://www.iacis.org). Our objective in pursuing this analysis of the research is multifaceted. Primarily through the use of keywords in the published papers, and augmented by post-hoc analysis of the corpus of our text data, we identify main topics and themes addressed by IACIS members, along with thematic evolution over time. For example, the theme of 'virtual worlds' became prevalent in the mid-2000's, but becomes much less common (almost non-existent) by the mid-2010's. Such observations can give us insights into more enduring and foundational topics of our discipline, and highlight those that may be more fleeting or faddish. They can also help us to recognize gaps which exist within disciplinary research-gaps that are often unexpected and that may exist due to subconscious assumptions; to wit: we were surprised that for an organization whose name bears the term "Information Systems", the actual keywords 'information systems' are surprisingly uncommon in our collective research over the past two decades. Have we, as a scholarly organization made an assumption that our research is always on the topic of information systems, and if so, does that assumption bear any expected or unintended consequences? 
We present here our initial findings of analysis of twenty years of IIS and IACIS research. The prepared data set is rich, provides interesting results, and represents extensive opportunity for additional inquiry. As one illustration, we identify, but do not address in this paper, the existence of 'research social networks' - collaborations between research partners that span multiple years, sometimes on a common theme but often on diverse topics. Our intent with this publication is to provide IACIS members, IIS readers, and other interested constituencies with meaningful reflection, current standing, and future opportunity for research in IS and IT.

\section{LITERATURE REVIEW}

Peslak (2018) outlined the publication history of Issues in Information Systems and the vision and mission of its publisher International Association of Computer Information Systems (IACIS): "IACIS and IIS are thus a significant and important forum for the exchange of current topics related to information systems, computer science, and related technology in support of business, academia, and other relevant organizations.” For the past 20 years, IIS and the associated annual conferences of IACIS have been important scholarly, professional venues for thousands of researchers around the world. The body of knowledge contributed by IACIS member-scholars has been significant, through the creation of research partnerships, collaborations and professional development opportunities. As with any such organization, periodic review of the body of work produced can provide insights into accomplishments, risks, and opportunities for the future.

Empirical retrospectives into the work product of scholarly groups has long been recognized as an important method of research validation and gap analysis (Foley-Nipcon \& Lee, 2012; Stanciu, Ionescu, Aleca \& Milhai, 2010). Close examination of organizational research can help to identify significant collaborations and collaborators, which can establish subject matter expertise and strengthen synergies between professionals in the discipline; including critical cultivation of new colleagues (Borromeo, Schleyer, Becich, \& Hochheiser, 2014; Ghobadi \& Robey, 2017; Serenko, 2013). Such analyses include identification of biases, specifically Selection Bias (Richardson, 2013), Anchoring (Zou \& Sun, 2020), and Availability Heuristc (Li \& Zhao, 2015); as well as the more positive benefits of improved disciplinary standardization (Beck, Koch, \& Weiskopf, 2016), elemental focus (Cheng, Huang, Yu, \& Wu, 2018; Choi, Yi, \& Lee, 2011; Jiang-Liang, \& Fong-Hsin, 2004), and congruence of future directions for the field (Coşkun, Özdağoğlu, Damar, \& Çallı, 2019; Maisonobe, 2019).

Empirical retrospective analysis of research within professional organizations is well-established and extensive. Dwivedi, Lal, Mustafee, \& Williams (2009) established a method for profiling research in information systems, however this type of examination is not unique to any one discipline (Armfield, , Edirippulige, Caffery, Bradford, Grey, \& Smith, 2014; Davidson, Baird, \& Prince, 2018; Zhang, Huang, Yu, \& Yang, 2017). Specifically within the fields of information systems and technology, retrospectives of ten (Ghobadi \& Robey, 2017; Tian, Wen \& Hong, 2008), twenty (Beydoun, Abedin, Merigó, \& Vera, 2019; Li \& Zhao, 2015), and even fifty years of research (Merigo, Pedrycz, Weber \& de la Sotta, 2018; Shukla, Merigó, Lammers \& Miranda, 2020) have summarized salient themes, topics and trends (Love, \& Hirschheim, 2016). Close examinations of scholarly organizations' research over time has led to significant, fruitful collaborations - to the benefit of the involved parties and their audiences (Ghobadi \& Robey, 2017; Kuo-Chung, Hsin-Ke \& Wen-I, 2018; Sohn \& Jung, 2015).

Identifying and creating effective collaborations is not the only, nor perhaps even the most important outcome of research corpus analyses. Scholars should hold themselves to the highest standards of accuracy, integrity and objectivity when publishing their work. Research retrospectives assist in this critical aspect of scholarly work by identifying weaknesses, limitations and errors in previously published works (Du, Ke, Chu \& Chan, 2017; Pereira, Verocai, Cordeiro \& Gomes, 2016). They also help to ensure that past, current and future publications within a given discipline develop and adhere to consistent terminology, practices and expectations (Du, et al., 2017; Kipp, 2005; Stauffer, 2017).

In this paper, we seek to build upon the literature cited in this section to the benefit of the IACIS research community, including engendering an environment that will welcome new scholars to the fold. An honest, thorough and objective review of our own work will contribute to a stronger and more vibrant intellectual community (Larsen, Monarchi, Hovorka \& Bailey, 2008). It can help us to develop better methods for identifying potential research partners and forming collaborations (Liu, Yang, Ma, Xu \& Hua, 2019; Mezzanzanica, Mercorio, Cesarini, Moscato \& Picariello, 2018). And it can assist in ensuring that the work we collectively produce is of sufficient quality to 
leave a meaningful legacy within our discipline (Piryani, Madhavi, \& Singh, 2017; Zhu, Kong, Hong, Li \& He, 2015).

\section{RESEARCH METHODOLOGY}

Our research focuses on the corpus of articles published in Issues in Information Systems from 2000 to 2019. The breadth and depth of the journal's coverage as well as its open access publishing format provided a strong foundation for the analysis of keywords described below. The data were collected with a Python program for extracting keywords from PDF files followed by a manual data cleansing process for error correction. The program downloaded the target page for a specific volume and issue of the journal such as http://www.iacis.org/iis/iis_articles.php?volume=20\&issue=4. The code parsed the target page with the Beautiful Soup library to extract the title and download link for each paper. For each PDF file on the target page, the program performed the following steps. First, the Wand library (wrapper for ImageMagick) converted PDF files to a series of JPG images, one per page. Second, the pytesseract library (wrapper for Tesseract-OCR Engine) extracted the keywords and other metadata from the first JPG image. Finally, the extracted keywords and metadata were stored in a MySQL database for further processing. The manual correction process included correcting OCR (Optical Character Recognition) extraction errors, addressing shifts in editorial policy and article formatting, and reviewing keywords from articles where automatic extraction was not possible. Table 1 summarizes the results of the extraction process by publication year.

Table 1. Summary Statistics for Image Processing per Publication Year

\begin{tabular}{|c|c|c|c|c|}
\hline Publication Year & Total \# of Articles & $\begin{array}{c}\text { Articles Requiring } \\
\text { Manual Processing }\end{array}$ & $\begin{array}{c}\text { Articles with no } \\
\text { Keywords }\end{array}$ & $\begin{array}{c}\text { Distinct } \\
\text { Keywords }\end{array}$ \\
\hline 2000 & 76 & 10 & 1 & 298 \\
\hline 2001 & 74 & 16 & 0 & 296 \\
\hline 2002 & 101 & 9 & 0 & 393 \\
\hline 2003 & 115 & 5 & 0 & 449 \\
\hline 2004 & 108 & 2 & 0 & 409 \\
\hline 2005 & 113 & 1 & 0 & 453 \\
\hline 2006 & 141 & 1 & 8 & 499 \\
\hline 2007 & 123 & 10 & 8 & 444 \\
\hline 2008 & 118 & 9 & 3 & 457 \\
\hline 2009 & 114 & 15 & 7 & 436 \\
\hline 2010 & 124 & 10 & 5 & 437 \\
\hline 2011 & 93 & 9 & 3 & 362 \\
\hline 2012 & 93 & 7 & 0 & 383 \\
\hline 2013 & 107 & 3 & 0 & 398 \\
\hline 2014 & 102 & 6 & 1 & 443 \\
\hline 2015 & 110 & 3 & 3 & 443 \\
\hline 2016 & 110 & 2 & 0 & 431 \\
\hline 2017 & 82 & 0 & 1 & 363 \\
\hline 2018 & 96 & 1 & 0 & 425 \\
\hline 2019 & 91 & 0 & $\mathbf{4 0}$ & 375 \\
\hline TOTAL & $\mathbf{2 0 9 1}$ & $\mathbf{1 1 9}$ & & $\mathbf{5 3 5 4}$ \\
\hline
\end{tabular}

Research Question 1 (RQ1): What are the keywords with the highest total usage?

To address research question 1, we aggregate a simple count of keywords across all volumes and issues of the journal to establish the highest total usage. The question casts light on the research themes in IIS overall and provides an important point of comparison with other research studies (Beydoun, Abedin, Merigó \& Vera, 2019; Dwivedi, Lal, Mustafee \& Williams, 2009). 
Research Question 2 (RQ2): What are the keywords used most consistently over time?

Research question 2 considers the influence of specific keywords over time by highlighting the long-running conversations in the journal. We tally the number of publication years in which a keyword appears at least once. If a keyword receives a score of 20, this means that the keyword appeared at least once in all 20 publication years under review for this study. In essence, the question aims to find the keywords representing the continuity of scholarship in a journal.

Research Question 3 (RQ3): What are the keywords with the greatest change in usage over time?

Research question 3 tracks the keywords with rapid changes in usage. We calculate the difference (delta) between the maximum number of references in a publication year and the minimum number of references in a publication year (excluding zero values) for each keyword. The resulting keywords represent changes in scholarship over time related to specific areas of research.

\section{RESULTS}

This section places the results for each research question in context by comparing results to pertinent research specific to IIS as well as other journals in the field.

\section{Research Question 1 (RQ1)}

Our results for RQ1, overall, bear similarities to other research on the publication history of Issues in Information Systems. Table 2 presents the top twenty-one keywords according to total references. The results share many common elements with Peslak's analysis of titles in IIS from 2000-2017 (2018). For example, six of seven singleword keywords in Table 2 overlap with the one-word occurrences identified by Peslak (2018, p. 45), including: privacy, security, ERP, curriculum, internet and cybersecurity. Furthermore, eight of 19 keywords in Table 2 overlap with the two-word occurrences in Peslak's study, including: information systems, e-commerce, information technology, e-learning, knowledge management, higher education, business intelligence and social media.

The results demonstrate a similar thematic unity with other information systems publications. Love and Hirschheim (2016) identified thematic clusters for the AIS Senior Scholars' Basket of Journals (SSB8) from 1991 to 2013. Their work identified e-commerce, knowledge management and security/risk/privacy as thematic clusters with clear analogues in our keyword list. Moreover, their specific analysis of Information Systems Journal includes thematic clusters such as security and ethics/critical research (Love \& Hirschheim, 2016). In their study of Information Systems Frontiers from 1999 to 2008, Dwivedi, Lal, Mustafee and Williams (2009) identified knowledge management, security, information systems and information technology among the journal's top 23 keywords. A later study of Information Systems Frontiers from 1999 to 2018 also identified knowledge management as a top theme (Beydoun, Abedin, Merigó, \& Vera, 2019).

Table 2. Top Twenty-One Keywords (Total References)

\begin{tabular}{|l|c|}
\hline \multicolumn{1}{|c|}{ Keyword } & Total References \\
\hline information systems & 69 \\
\hline information technology (IT) & 68 \\
\hline e-commerce & 62 \\
\hline information technology & 57 \\
\hline security & 56 \\
\hline knowledge management & 48 \\
\hline privacy & 43 \\
\hline social media & 42 \\
\hline e-learning & 41 \\
\hline
\end{tabular}




\begin{tabular}{|l|c|}
\hline \multicolumn{1}{|c|}{ Keyword } & Total References \\
\hline ERP & 38 \\
\hline ethics & 37 \\
\hline internet & 37 \\
\hline information security & 36 \\
\hline project management & 36 \\
\hline curriculum & 35 \\
\hline higher education & 34 \\
\hline cybersecurity & 33 \\
\hline online learning & 32 \\
\hline distance education & 30 \\
\hline data mining & 29 \\
\hline business intelligence & 29 \\
\hline
\end{tabular}

While the results suggest robust participation in the main themes of information systems research broadly, they also suggest some specific areas where IIS contributes uniquely to information systems research. For example, five of the 21 top keywords relate to education: e-learning, curriculum, higher education, online learning, and distance learning. Neither the SSB8 thematic clusters nor the Information Systems Journal thematic clusters (Love \& Hirschheim, 2016) nor the Information Systems Frontiers keywords (Beydoun, Abedin, Merigó, \& Vera, 2019; Dwivedi, Lal, Mustafee \& Williams, 2009) identified education as a significant research theme. Somewhat surprisingly, project management also received no explicit reference in the studies reviewed although some components of project management are mentioned such as IS management, requirements/specification process, development methodology, IS design/development, and development (Love \& Hirschheim, 2016).

\section{Research Question 2 (RQ2)}

Research question 2 aims to reveal the long-running, continuous conversations in IIS by identifying the keywords used most consistently over time in the journal. Table 3 summarizes these long-running conversations by sorting the keywords based on the number of publication years in which they are mentioned. In other words, a value of 20 would mean that the keyword was used at least once in every publication year of IIS under review (2000-2019). These results represent the enduring and foundational aspects of our research community, if not always the most popular research themes overall.

In a few cases, the enduring and foundational topics in IIS reflect those in the IS literature at large. As discussed in the previous section, knowledge management constitutes an important research theme broadly in the information systems literature. The results of our study demonstrate that knowledge management is referenced as a keyword in every publication year but one, and only the keyword 'information systems' is used as regularly over time. Similarly, keywords related to security are mentioned in almost every publication year: security, privacy, and information security.

Table 3. Top Twenty-One Keywords (Total Number of Years Referenced)

\begin{tabular}{|l|c|c|c|c|c|}
\hline \multicolumn{1}{|c|}{ Keyword } & \# of Years & Max \# & Min \# & Delta & Total \\
\hline information systems & 19 & 6 & 1 & 5 & 69 \\
\hline knowledge management & 19 & 6 & 1 & 5 & 48 \\
\hline security & 18 & 10 & 1 & 9 & 56 \\
\hline information technology & 18 & 6 & 1 & 5 & 57 \\
\hline project management & 18 & 3 & 1 & 2 & 36 \\
\hline e-learning & 17 & 11 & 1 & 10 & 41 \\
\hline curriculum & 17 & 6 & 1 & 5 & 35 \\
\hline ethics & 17 & 5 & 1 & 4 & 37 \\
\hline privacy & 17 & 5 & 1 & 4 & 43 \\
\hline
\end{tabular}




\begin{tabular}{|l|c|c|c|c|c|}
\hline \multicolumn{1}{|c|}{ Keyword } & \# of Years & Max \# & Min \# & Delta & Total \\
\hline e-commerce & 16 & 13 & 1 & 12 & 62 \\
\hline data mining & 16 & 6 & 1 & 5 & 29 \\
\hline online education & 16 & 4 & 1 & 3 & 24 \\
\hline information technology (it) & 15 & 10 & 1 & 9 & 68 \\
\hline ERP & 15 & 6 & 1 & 5 & 38 \\
\hline business intelligence & 15 & 5 & 1 & 4 & 29 \\
\hline distance education & 15 & 3 & 1 & 2 & 30 \\
\hline online learning & 14 & 5 & 1 & 4 & 32 \\
\hline information security & 14 & 5 & 1 & 4 & 36 \\
\hline assessment & 14 & 5 & 1 & 4 & 24 \\
\hline e-government & 14 & 4 & 1 & 3 & 22 \\
\hline pedagogy & 14 & 3 & 1 & 2 & 21 \\
\hline
\end{tabular}

Some of the journal's long-running conversations highlight the unique contributions of IIS. Seven of the 21 keywords in Table 3 relate to education: e-learning, curriculum, online education, distance education, online learning, assessment and pedagogy. Project management is as consistently referenced over time as the keywords security and information technology. Finally, e-government provides the most dramatic example of an on-going conversation in the journal without the peaks and valleys of more faddish topics. Figure 1 shows the longitudinal usage of each keyword in Table 3. E-government routinely appears once or twice in most publication years with only a small peak in 2008 and 2009.

\begin{tabular}{|c|c|c|c|c|c|c|c|c|c|c|c|c|c|c|c|c|c|c|c|c|c|}
\hline Keyword & 2000 & 2001 & 2002 & 2003 & 2004 & 2005 & 2006 & 2007 & 2008 & 2009 & 2010 & 2011 & 2012 & 2013 & 2014 & 2015 & 2016 & 2017 & 2018 & 2019 & Years \\
\hline information systems & 3 & 1 & 2 & 4 & 3 & 2 & 6 & 4 & 3 & 3 & 6 & 3 & 5 & 0 & 2 & 3 & 5 & 4 & 5 & 5 & 19 \\
\hline knowledge management & 2 & 3 & 1 & 0 & 1 & 3 & 4 & 3 & 2 & 2 & 1 & 3 & 1 & 4 & 3 & 2 & 6 & 3 & 2 & 2 & 19 \\
\hline security & 1 & 1 & 2 & 4 & 1 & 0 & 3 & 4 & 3 & 3 & 4 & 3 & 4 & 1 & 1 & 4 & 6 & 1 & 0 & 10 & 18 \\
\hline information technology & 4 & 1 & 2 & 3 & 4 & 4 & 3 & 0 & 5 & 5 & 2 & 4 & 2 & 3 & 1 & 6 & 1 & 3 & 4 & 0 & 18 \\
\hline project management & 2 & 1 & 1 & 1 & 2 & 2 & 2 & 1 & 2 & 2 & 3 & 3 & 0 & 0 & 1 & 2 & 3 & 3 & 3 & 2 & 18 \\
\hline e-learning & 0 & 1 & 2 & 0 & 1 & 11 & 1 & 2 & 2 & 2 & 2 & 1 & 2 & 1 & 3 & 3 & 3 & 0 & 3 & 1 & 17 \\
\hline curriculum & 1 & 1 & 2 & 3 & 3 & 2 & 6 & 2 & 1 & 0 & 2 & 2 & 2 & 1 & 0 & 1 & 2 & 3 & 0 & 1 & 17 \\
\hline ethics & 0 & 1 & 1 & 1 & 2 & 1 & 4 & 5 & 0 & 3 & 3 & 2 & 1 & 1 & 5 & 1 & 3 & 1 & 2 & 0 & 17 \\
\hline privacy & 0 & 0 & 1 & 4 & 1 & 0 & 1 & 1 & 2 & 2 & 4 & 2 & 2 & 2 & 2 & 5 & 5 & 2 & 3 & 4 & 17 \\
\hline e-commerce & 6 & 13 & 8 & 6 & 6 & 4 & 7 & 1 & 1 & 2 & 2 & 1 & 2 & 0 & 0 & 0 & 0 & 1 & 1 & 1 & 16 \\
\hline data mining & 1 & 0 & 2 & 2 & 2 & 1 & 0 & 6 & 1 & 2 & 2 & 1 & 2 & 1 & 0 & 2 & 1 & 0 & 1 & 2 & 16 \\
\hline online education & 0 & 1 & 1 & 2 & 2 & 1 & 2 & 1 & 0 & 0 & 1 & 3 & 1 & 1 & 1 & 0 & 4 & 1 & 1 & 1 & 16 \\
\hline information technology (it) & 0 & 0 & 0 & 1 & 0 & 1 & 5 & 8 & 7 & 1 & 3 & 3 & 5 & 7 & 5 & 4 & 10 & 3 & 5 & 0 & 15 \\
\hline $\operatorname{erp}$ & 1 & 3 & 3 & 0 & 1 & 2 & 6 & 3 & 3 & 3 & 1 & 3 & 0 & 0 & 0 & 2 & 0 & 2 & 2 & 3 & 15 \\
\hline business intelligence & 0 & 0 & 0 & 0 & 1 & 2 & 1 & 2 & 1 & 5 & 2 & 2 & 3 & 0 & 2 & 3 & 1 & 1 & 2 & 1 & 15 \\
\hline distance education & 3 & 2 & 3 & 2 & 1 & 3 & 3 & 2 & 1 & 1 & 1 & 2 & 3 & 0 & 0 & 0 & 0 & 1 & 2 & 0 & 15 \\
\hline online learning & 2 & 1 & 0 & 0 & 0 & 5 & 2 & 2 & 1 & 0 & 4 & 3 & 2 & 0 & 1 & 3 & 2 & 1 & 3 & 0 & 14 \\
\hline information security & 0 & 1 & 0 & 0 & 0 & 3 & 2 & 0 & 2 & 3 & 4 & 1 & 2 & 3 & 2 & 5 & 4 & 1 & 0 & 3 & 14 \\
\hline assessment & 0 & 1 & 1 & 0 & 3 & 1 & 5 & 4 & 2 & 1 & 1 & 1 & 1 & 0 & 1 & 1 & 0 & 1 & 0 & 0 & 14 \\
\hline e-government & 0 & 0 & 2 & 1 & 0 & 1 & 2 & 1 & 3 & 4 & 1 & 1 & 1 & 2 & 1 & 1 & 1 & 0 & 0 & 0 & 14 \\
\hline pedagogy & 1 & 2 & 2 & 1 & 1 & 3 & 1 & 1 & 0 & 1 & 0 & 0 & 0 & 0 & 1 & 3 & 1 & 0 & 1 & 2 & 14 \\
\hline
\end{tabular}

Figure 1. Top Twenty-One Keywords (Total Number of Years Referenced) by Publication Year

\section{Research Question 3 (RQ3)}

In contrast to research question 2, RQ3 addresses the rapidly shifting trends and terms associated with emerging developments in the field. Table 4 displays the top nineteen keywords based on their delta score, the difference between their maximum and minimum usage in a publication year. The keyword 'e-commerce' serves as an important example of how changes over time provide insights into the development of an academic discipline. Figure 2 presents the number of papers referencing each keyword per publication year. Journal articles discussed ecommerce intensely in the 2000s with 13 references in 2001. By 2013, however, the keyword is used considerably less often. The results are remarkably consistent with Peslak's findings: "The largest decline in mentions is for e- 


\section{Issues in Information Systems \\ Volume 21, Issue 1, pp. 249-259, 2020}

commerce....Clearly there is a maturing of this topic and new research has slowed dramatically." (2018, p. 43; see also Dennis, 2017). This shift can also be explained, at least partially, by shifts in societal perception-what was explicitly e-commerce in 2005, is today assumed to be just regular commerce (Dennis, 2017). Cybersecurity, on the other hand, demonstrates a topic very much on the rise. With no mentions prior to 2014, cybersecurity earned 33 attributions in just 5 years.

The results highlight other examples of falling and rising trends. Collaboration, for example, spiked in 2004 and maintained a robust presence in the journal until 2009, but only one paper referenced the keyword in the last ten years. Social networking also experienced a bump in 2010 that significantly leveled off by 2015. Similarly, cloud computing and big data had usage increases in 2015. Higher education demonstrates the most consistent and recent growth in keyword references with robust discussion beginning in 2016 and continuing to 2019. The discussion section of the paper will expand upon these results to place them in the proper critical perspective.

Table 4. Top Nineteen Keywords (Highest Delta)

\begin{tabular}{|l|c|c|c|c|c|}
\hline \multicolumn{1}{|c|}{ Keyword } & \# of Years & Max \# & Min \# & Delta & Total \\
\hline e-commerce & 16 & 13 & 1 & 12 & 62 \\
\hline cybersecurity & 5 & 13 & 2 & 11 & 33 \\
\hline e-learning & 17 & 11 & 1 & 10 & 41 \\
\hline security & 18 & 10 & 1 & 9 & 56 \\
\hline information technology (IT) & 15 & 10 & 1 & 9 & 68 \\
\hline higher education & 13 & 8 & 1 & 7 & 34 \\
\hline big data & 7 & 8 & 1 & 7 & 19 \\
\hline social networking & 9 & 7 & 1 & 6 & 21 \\
\hline collaboration & 8 & 7 & 1 & 6 & 20 \\
\hline information systems & 19 & 6 & 1 & 5 & 69 \\
\hline knowledge management & 19 & 6 & 1 & 5 & 48 \\
\hline information technology & 18 & 6 & 1 & 5 & 57 \\
\hline curriculum & 17 & 6 & 1 & 5 & 35 \\
\hline data mining & 16 & 6 & 1 & 5 & 29 \\
\hline ERP & 15 & 6 & 1 & 5 & 38 \\
\hline IS curriculum & 13 & 6 & 1 & 5 & 25 \\
\hline distance learning & 13 & 6 & 1 & 5 & 27 \\
\hline cloud computing & 9 & 6 & 1 & 5 & 20 \\
\hline enterprise resource planning & 8 & 6 & 1 & 5 & 19 \\
\hline
\end{tabular}

\begin{tabular}{|c|c|c|c|c|c|c|c|c|c|c|c|c|c|c|c|c|c|c|c|c|c|}
\hline Keyword & 2000 & 2001 & 2002 & 2003 & 2004 & 2005 & 2006 & 2007 & 2008 & 2009 & 2010 & 2011 & 2012 & 2013 & 2014 & 2015 & 2016 & 2017 & 2018 & 2019 & Delta \\
\hline e-commerce & 6 & 13 & 8 & 6 & 6 & 4 & 7 & 1 & 1 & 2 & 2 & 1 & 2 & 0 & 0 & 0 & 0 & 1 & 1 & 1 & 12 \\
\hline cybersecurity & 0 & 0 & 0 & 0 & 0 & 0 & 0 & 0 & 0 & 0 & 0 & 0 & 0 & 0 & 0 & 2 & 9 & 5 & 4 & 13 & 11 \\
\hline e-learning & 0 & 1 & 2 & 0 & 1 & 11 & 1 & 2 & 2 & 2 & 2 & 1 & 2 & 1 & 3 & 3 & 3 & 0 & 3 & 1 & 10 \\
\hline security & 1 & 1 & 2 & 4 & 1 & 0 & 3 & 4 & 3 & 3 & 4 & 3 & 4 & 1 & 1 & 4 & 6 & 1 & 0 & 10 & 9 \\
\hline information technology (it) & 0 & 0 & 0 & 1 & 0 & 1 & 5 & 8 & 7 & 1 & 3 & 3 & 5 & 7 & 5 & 4 & 10 & 3 & 5 & 0 & 9 \\
\hline higher education & 0 & 1 & 0 & 1 & 0 & 1 & 2 & 2 & 1 & 1 & 0 & 2 & 0 & 0 & 1 & 0 & 6 & 5 & 3 & 8 & 7 \\
\hline big data & 0 & 0 & 0 & 0 & 0 & 0 & 0 & 0 & 0 & 0 & 0 & 0 & 1 & 1 & 1 & 8 & 4 & 0 & 2 & 2 & 7 \\
\hline social networking & 0 & 0 & 0 & 0 & 0 & 0 & 0 & 0 & 0 & 2 & 7 & 2 & 3 & 3 & 1 & 0 & 1 & 1 & 1 & 0 & 6 \\
\hline collaboration & 1 & 0 & 0 & 1 & 7 & 1 & 4 & 0 & 2 & 3 & 0 & 0 & 0 & 0 & 0 & 0 & 0 & 0 & 0 & 1 & 6 \\
\hline information systems & 3 & 1 & 2 & 4 & 3 & 2 & 6 & 4 & 3 & 3 & 6 & 3 & 5 & 0 & 2 & 3 & 5 & 4 & 5 & 5 & 5 \\
\hline knowledge management & 2 & 3 & 1 & 0 & 1 & 3 & 4 & 3 & 2 & 2 & 1 & 3 & 1 & 4 & 3 & 2 & 6 & 3 & 2 & 2 & 5 \\
\hline information technology & 4 & 1 & 2 & 3 & 4 & 4 & 3 & 0 & 5 & 5 & 2 & 4 & 2 & 3 & 1 & 6 & 1 & 3 & 4 & 0 & 5 \\
\hline curriculum & 1 & 1 & 2 & 3 & 3 & 2 & 6 & 2 & 1 & 0 & 2 & 2 & 2 & 1 & 0 & 1 & 2 & 3 & 0 & 1 & 5 \\
\hline data mining & 1 & 0 & 2 & 2 & 2 & 1 & 0 & 6 & 1 & 2 & 2 & 1 & 2 & 1 & 0 & 2 & 1 & 0 & 1 & 2 & 5 \\
\hline erp & 1 & 3 & 3 & 0 & 1 & 2 & 6 & 3 & 3 & 3 & 1 & 3 & 0 & 0 & 0 & 2 & 0 & 2 & 2 & 3 & 5 \\
\hline is curriculum & 0 & 0 & 0 & 1 & 2 & 1 & 1 & 0 & 0 & 6 & 2 & 3 & 3 & 1 & 2 & 0 & 1 & 0 & 1 & 1 & 5 \\
\hline distance learning & 6 & 2 & 2 & 2 & 2 & 3 & 2 & 0 & 0 & 0 & 2 & 1 & 1 & 0 & 2 & 1 & 0 & 1 & 0 & 0 & 5 \\
\hline cloud computing & 0 & 0 & 0 & 0 & 0 & 0 & 0 & 0 & 1 & 1 & 0 & 2 & 0 & 1 & 5 & 6 & 1 & 0 & 1 & 2 & 5 \\
\hline enterprise resource planning & 0 & 1 & 0 & 0 & 0 & 2 & 6 & 1 & 2 & 5 & 0 & 1 & 0 & 0 & 0 & 0 & 0 & 1 & 0 & 0 & 5 \\
\hline
\end{tabular}

Figure 2. Top Nineteen Keywords (Highest Delta) by Publication Year 


\section{DISCUSSION}

On the whole, our results demonstrate that the research themes in IIS are broadly consistent with those in other information systems publications. The following passage summarizing results for the journal ISF reflects the highlevel aspects of our findings for IIS: "The analysis revealed that ISF paper topics fall largely into two groups: one group represents a stable anchor of topics within the traditional IS themes. Another group reflects ISF research adapting and responding to key trends as they emerge." (Beydoun, Abedin, Merigó, \& Vera, 2019). The results from RQ1 and RQ2 reveal stable anchor topics (i.e. enduring and foundational topics) in the discipline such as knowledge management, while the RQ3 results capture attempts of the IIS community to adapt and respond to emerging trends in the discipline like cloud computing.

To learn more about how the IIS corpus relates to research themes in computing, we performed an exact match comparison of IIS keywords with the ACM Computing Classification System taxonomy (Association for Computing Machinery, 2012) to identify the distribution of keywords in the Level 1 categories of the taxonomy. Figure 3 presents the results of this analysis with a clear skew toward topics in information systems and applied computing, and away from themes more closely aligned with information technology or the mathematical foundations of the discipline. While the analysis is flawed as it represents a small sample of the more than 9000 keyword references in the corpus, the results prompt reflection about the thematic content of our research community.

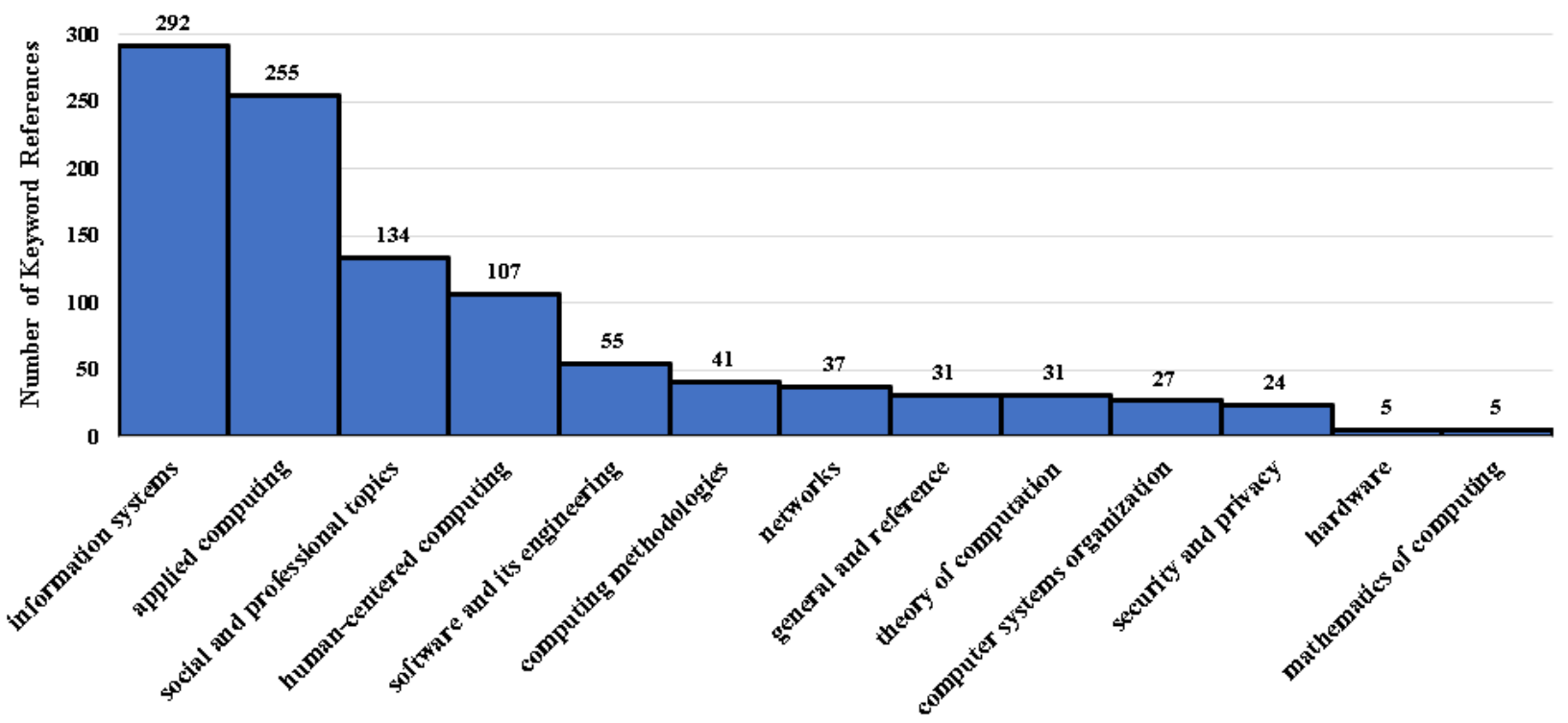

Figure 3. IIS Keyword References by ACM Computing Classification System Level 1 Categories

This discussion would not be complete without an assessment of the limitations of this study. The study suffers from several kinds of bias. First, we have evidence of sampling bias or more specifically an incomplete set of papers related to the corpus. For example, our paper counts do not match the paper counts reported by Peslak (2018). With over 2,000 papers in the corpus we cannot guarantee that every paper was discovered. Second, 40 articles in the corpus did not include keywords at all and we cannot assume that these articles represent a random set in the corpus. Third, the data extraction process with both its automated and manual components is highly effective, yet imperfect. We cannot dismiss the possibility that the approach taken and the technology employed introduced errors in a nonrandom way. Finally, we noted a conference theme bias in which, not surprisingly, keywords receive bumps in usage when they overlap with conference themes. For example, cybersecurity references spike in 2016 and 2019 when the term was included as a conference theme in those years. This bias in particular challenges our efforts at comparing the IIS corpus with other journals in the discipline. 


\section{Issues in Information Systems}

Volume 21, Issue 1, pp. 249-259, 2020

Linguistic inconsistencies and ambiguities also limit the interpretive value of the study. For example, some keywords will be systematically undercounted due to the many variations available to authors. Information systems was presented in all of the following ways: information systems, information system, and information systems (IS). In some cases, compound keywords are ambiguous. For example, the compound keyword, IT and ethics, placed at the end of a list of keywords might be considered a single compound keyword or two separate keywords (IT, ethics). We cannot rule out the possibility that other kinds of ambiguity also frustrate the interpretation of the data.

\section{CONCLUSION}

Our research has identified and analyzed 20 years of scholarly work as published in the volumes of Issues in Information Systems. Our identification of primary topical themes as outlined in the above tables will serve to guide scholars' formulation of their individual research agendas, by illuminating foundational versus faddish topics, and through the encouragement of inquiry that adds to the body of knowledge in the information systems profession. We find that our research, and specifically our creation of a corpus of data from IIS publications creates opportunities for additional investigation. Although we have identified gaps in research, and topics that burned brightly but then decreased or even vanished, we have not examined why such phenomena occurred over the time period examined. Such introspection could emerge from this paper as additional areas of research in order to enhance our collective contribution to our discipline.

\section{REFERENCES}

Armfield, N.R., Edirippulige, S., Caffery, L.J., Bradford, N.K., Grey, J.W. \& Smith, A.C. (2014). Telemedicine - A bibliometric and content analysis of 17,932 publication records. International Journal of Medical Informatics, 83(10), 715-725.

Association for Computing Machinery. (2012). 2012 ACM Computing Classification System. https://dl.acm.org/ccs

Beck, F., Koch, S. \& Weiskopf, D. (2016). Visual Analysis and Dissemination of Scientific Literature Collections with SurVis. IEEE Transactions on Visualization \& Computer Graphics, 22(1), 180-189.

Beydoun, G., Abedin, B., Merigó, J.M. \& Vera, M. (2019). Twenty Years of Information Systems Frontiers. Information Systems Frontiers, 21(2), 485-494.

Borromeo, C.D., Schleyer, T.K., Becich, M.J. \& Hochheiser, H. (2014). Finding Collaborators: Toward Interactive Discovery Tools for Research Network Systems. Journal of Medical Internet Research, 16, 11.

Cheng, F.F., Huang, Y.W., Yu, H.C. \& Wu, C.S. (2018). Mapping Knowledge Structure by Keyword Co-occurrence and Social Network Analysis. Library Hi Tech, 36(4), 636-65.

Choi, J., Yi, S. \& Lee, K.C. (2011). Analysis of Keyword Networks in MIS Research and Implications for Predicting Knowledge Evolution. Information \& Management, 48(8), 371-381.

Coşkun, E., Özdağoğlu, G., Damar, M. \& Çallı, B.A. (2019). Scientometrics-Based Study of Computer Science and Information Systems Research Community Macro Level Profiles. International Conference on Information Systems Post-Implementation \& Change Management, 180-188.

Davidson, E., Baird, A. \& Prince, K. (2018). Opening the Envelope of Health Care Information Systems Research. Information and Organization, 28(3), 140.

Dennis, S. (2017). The End of E-Commerce? These Days, It's All Just Commerce. Forbes, Electronic Version. Retrieved on 18 May 2020 from: https://www.forbes.com/sites/stevendennis/2017/10/02/the-end-of-ecommerce/\#5c113a10761d

Du, H.S., Ke, X., Chu, S.K.W. \& Chan, L.T. (2017). A Bibliometric Analysis of Emergency Management Using Information Systems (2000-2016). Online Information Review, 41(4), 454-470. 
Dwivedi, Y., Lal, B., Mustafee, N. \& Williams, M. (2009). Profiling a decade of Information Systems Frontiers' research. Information Systems Frontiers, 11(1), 87-102.

Foley-Nicpon, M. \& Lee, S. (2012). Disability Research in Counseling Psychology Journals: A 20-Year Content Analysis. Journal of Counseling Psychology, 59(3), 392-398.

Ghobadi, S. \& Robey, D. (2017). Strategic Signaling and Awards: Investigation into the first decade of AIS best publications awards. Journal of Strategic Information Systems, 26(4), 360.

Holmes, M. \& Hayen, R. (2010). A Preliminary Perspective of the 50-Year Publications in the Journal of Computer Information Systems. Issues in Information Systems, 11(1), 292-297.

Jiang-Liang, H. \& Fong-Hsin, L. (2004). A Document and User Matching Model via Document Keyword Analysis. Journal of Computer Information Systems, 44(4), 1-15.

Kipp, M.E.I. (2005). Complementary or Discrete Contexts in Online Indexing: A Comparison of User, Creator, and Intermediary Keywords. Canadian Journal of Information \& Library Sciences, 29(4), 419-436

Kuo-Chung, C., Hsin-Ke L. \& Wen-I, L. (2018). Identifying Emerging Relationships in Healthcare Domain Journals via Citation Network Analysis. Information Technology \& Libraries, 37(1), 39-51.

Larsen, K.R., Monarchi, D.E., Hovorka, D.S. \& Bailey, C.N. (2008). Analyzing unstructured text data: Using latent categorization to identify intellectual communities in information systems. Decision Support Systems, 45(4), 884-896.

Li, W. \& Zhao, Y. (2015). Bibliometric analysis of global environmental assessment research in a 20-year period. Environmental Impact Assessment Review, 50, 158-166.

Liu, Y., Yang, C., Ma, J., Xu, W. \& Hua, Z. (2019). A Social Recommendation System for Academic Collaboration in Undergraduate Research. Expert Systems, 36(2).

Love, J. \& Hirschheim, R. (2016). Reflections on Information Systems Journal's thematic composition. Information Systems Journal, 26(1), 21-38.

Maisonobe, M. (2019). The Future of Urban Models in the Big Data and AI Era: A bibliometric analysis (20002019), arXiv.

Merigo, J.M., Pedrycz, W., Weber, R. \& de la Sotta, C. (2018). Fifty years of Information Sciences: A bibliometric overview. Information Sciences, 432, 245-268.

Mezzanzanica, M., Mercorio, F., Cesarini, M., Moscato, V. \& Picariello, A. (2018). GraphDBLP: A system for analysing networks of computer scientists through graph databases. Multimedia Tools and Applications, 77(14), 18657-18688.

Pereira, F.C., Verocai, H.D., Cordeiro, V.R. \& Gomes, C.F.S. (2016). Information Systems (IS) and Innovation: Bibliometric study. Journal of Information Systems \& Technology Management, 13(1), 81.

Peslak, A. (2018). Information Technology Trends: A Longitudinal Study of Terms Used in Issues in Information Systems Titles. Issues in Information Systems, 19(1), 39-47.

Piryani, R., Madhavi, D. \& Singh, V. K. (2017). Analytical Mapping of Opinion Mining and Sentiment Analysis Research during 2000-2015. Information Processing \& Management, 53(1), 122-150.

Richardson, H.A.H. (2013). Revelations from the Literature. Computers in Libraries, 33(4), 12-17. 
Serenko, A. (2013). Meta-analysis of Scientometric Research of Knowledge Management: Discovering the identity of the discipline. Journal of Knowledge Management, 17(5), 773-812.

Shukla, N., Merigó, J.M., Lammers, T. \& Miranda, L. (2020). Half a Century of Computer Methods and Programs in Biomedicine: A bibliometric analysis from 1970 to 2017. In Computer Methods and Programs in Biomedicine. DOI: 10.1016/j.cmpb.2019.105075.

Sohn, B.S. \& Jung, J.E. (2015). A Novel Ranking Model for a Large-Scale Scientific Publication. Mobile Networks \& Applications, 20(4), 508-520.

Stanciu, A., Ionescu, I., Aleca, O.E. \& Mihai, F. (2010). A Research Profile for Management Information Systems Case Study Based on Publications in JAMIS and AMIS International Conference. Accounting \& Management Information Systems, 9(2), 329-341.

Stauffer, E. (2017). TechTrends 2010-2015: A Content Analysis. TechTrends: Linking Research \& Practice to Improve Learning, 61(2), 147-154.

Tian, Y., Wen, C. \& Hong, S. (2008). Global Scientific Production on GIS Research by Bibliometric Analysis from 1997 to 2006. Journal of Informetrics, 2(1), 65-74.

Webb, G. (2008). Using Google Keyword Statistics to Explain Changes in Traffic to Internet Sites Related to Global Environmental Management. Issues in Information Systems, 9(2), 111-116.

Zhang, Y., Huang, K., Yu, Y. \& Yang, B. (2017). Mapping of Water Footprint Research: A bibliometric analysis during 2006-2015. Journal of Cleaner Production, 149, 70-79.

Zhu, Y., Kim, M.C. \& Chen, C. (2017). An Investigation of the Intellectual Structure of Opinion Mining Research. Information Research: An International Electronic Journal, 22(1).

Zhu, Q., Kong, X., Hong, S., Li, J. \& He, Z. (2015). Global Ontology Research Progress: A bibliometric analysis. ASLIB Journal of Information Management, 67(1), 27-54.

Zou, L.X. \& Sun, L. (2020). Visualization Analysis of Health Informatics Research from 2001 to 2018. Current Science, 118(5), 714-721. 